\title{
Crescimento de Hymenaea courbaril L. var. stilbocarpa (Hayne) Lee et Lang. e Enterolobium contortisiliquum (Vell.) Morong (Leguminosae) sob diferentes níveis de sombreamento
}

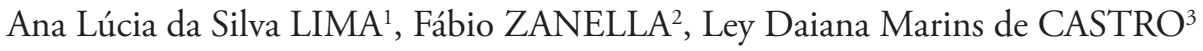 \\ RESUMO \\ Hymenaea courbaril L. var. stilbocarpa (Hayne) Lee et Lang. é uma espécie clímax tolerante a sombra, ao passo que Enterolobium \\ contortisiliquum (Vell.) Morong. é uma espécie pioneira. O desenvolvimento destas espécies pode refletir a habilidade de \\ adaptaçáo aos diferentes fatores ambientais (luz, água e temperatura) no local em que estáo crescendo. O suprimento inadequado \\ de um desses fatores pode reduzir o vigor da planta e limitar seu desenvolvimento. O presente trabalho teve como objetivo \\ avaliar os efeitos do nível de sombreamento no crescimento e a concentração de pigmentos fotossintéticos em duas espécies \\ de leguminosas arbóreas, Hymenaea courbaril L. var. stilbocarpa (Hayne) Lee et Lang. e Enterolobium contortisiliquum (Vell.) \\ Morong. O experimento foi conduzido no Setor de Olericultura do Centro Universitário Luterano de Ji-Paraná (CEULJI/ \\ ULBRA)/Rondônia. Durante a formação das mudas, ambas as espécies foram expostas a quatro tratamentos de sombra: $0 \%$ \\ (controle - sol pleno); $30 \% ; 50 \%$ e $80 \%$. Cada tratamento foi constituído com três repetições de cada espécie; o delineamento \\ experimental foi inteiramente casualisado. Quatro meses após a semeadura, as seguintes análises foram realizadas: número \\ de folhas, altura da planta, comprimento do sistema radicular, massa seca total e concentração de pigmentos fotossintéticos. \\ O tratamento sob sol pleno afetou negativamente o crescimento de ambas as espécies. As mudas crescidas sob 50\% e 80\% \\ apresentaram melhor desenvolvimento. Conforme o aumento do sombreamento houve um decréscimo na razão clorofila $a / b$ \\ e um aumento nas concentraçóes de clorofila total e carotenóides totais.
}

PALAVRAS-CHAVE: Hymenaea courbaril, Enterolobium contortisiliquum, sombreamento, crescimento, pigmentos fotossintéticos.

\section{Growth of Hymenaea courbaril L. var. stilbocarpa (Hayne) Lee et Lang. e Enterolobium contortisiliquum (Vell.) Morong (Leguminosae) under different shading levels}

\begin{abstract}
Hymenaea courbaril L. var. stilbocarpa (Hayne) Lee et Lang. is a clímax shadow tolerant specie and Enterolobium contortisiliquum (Vell.) Morong., by the other hand, is considered as a pioneer specie. The development of these species may reflect its adaptation ability to different environmental elements (light, water and temperature) at its growth site. An inadequate supply of some of these elements may reduce plant vigor and limit its development. This work aimed to evaluate the effects of shade intensity on the growth and photosynthetic pigment concentration of two arboreal legumes that are typical to northern Brazil, namely, the Hymenaea courbaril L. var. stilbocarpa (Hayne) Lee et Lang. and the Enterolobium contortisiliquum (Vell.) Morong. The experiment was carried out at the Centro Universitário Luterano de Ji-Paraná (CEULJ/ULBRA)/Rondônia. During the formation of the seedlings, both species were exposed to four treatments of shade: $0 \%$ (control - without shade); $30 \% ; 50$ $\%$ e $80 \%$. Each treatment was carried out with three replications for each species; the experimental design was completely randomized. Four month after sowing, the following analyses were carried out: number of leaves, plant height, roots length, dry mass and photosynthetic pigment concentration. The treatment under $0 \%$ shade impaired the seedling growth of both species. The most favorable treatments were $50 \%$ and $80 \%$ shade. According to the shade intensity, the chlorophyll $a / b$ ratio decreased and the chlorophyll and carotenoids increased.
\end{abstract}

KEYWORDS: Hymenaea courbaril, Enterolobium contortisiliquum, shading, growth, photosynthetic pigments.

\footnotetext{
1 Centro Universitário Luterano de Ji-Paraná, CEULJ/ULBRA, e-mail: limaals@yahoo.com.br

Instituto Federal de Rondônia/Campus de Ji-Paraná, e-mail: zanellaf@yahoo.com.br

Centro Universitário Luterano de Ji-Paraná, CEULJ/ULBRA, e-mail: leydaianajp@hotmail.com
} 


\section{INTRODUÇÃO}

Fatores como luz, água e temperatura são alguns dos elementos do ambiente que influenciam no desenvolvimento da vegetação. $\mathrm{O}$ suprimento inadequado de um desses fatores pode reduzir o vigor da planta e limitar seu desenvolvimento (Lima Júnior, 2006). Por exemplo, quando as plantas são expostas à alta irradiância, o balanço entre a produção de espécies reativas de oxigênio e os mecanismos de defesa das plantas podem ser alterados, resultando normalmente em danos às células (Lima et al., 2002).

Geralmente há uma extensa diversidade de respostas das plantas à intensidade luminosa (Scalon \& Alvarenga, 1993). Zanella et al. (2006) verificaram em plantas de maracujá com 90 dias após a semeadura, que o crescimento foi prejudicado sob sol pleno, sendo os níveis de sombreamento $50 \%$ e $80 \%$ os mais favoráveis. Esses autores constaram redução na razão clorofila $a / b$ e um aumento dos teores de clorofila total e decréscimo na concentraçáo de carotenóides totais com o aumento do sombreamento. Mudas de Bombacopsis glabra (Pasq.) A. Robyns (castanha-do-maranhão) submetidas ao sol pleno e $50 \%$ de sombra apresentam maior altura, maior clorofila total e menor relação clorofila $a l b$, sob $50 \%$ (Scalon et al., 2003). Almeida et. al. (2005) constataram em mudas Jacaranda puberula expostas a pleno sol alto índice de mortalidade e o tratamento com $30 \%$ de sombreamento mostrou-se superior aos demais em todas as variáveis estudadas.

Segundo alguns autores os parâmetros morfológicos e fisiológicos mais utilizados para verificar a qualidade de mudas de espécies arbóreas submetidas a diferentes níveis de sombreamentos são altura da planta, massa seca total, relação clorofila $a / b$, conteúdo de clorofila total e carotenóide total (Engel, 1989; Ferraz \& Silva, 2001; Chaves \& Paiva, 2004).

Estudos relacionando a intensidade luminosa à produçáo de mudas de espécies arbóreas de boa qualidade são de extrema importância para o desenvolvimento da atividade florestal e para programas de conservação (Monteiro \& Ramos, 1997) e reflorestamento.

Nos ecossistemas brasileiros, as leguminosas são muito bem representadas em diversidade e densidade, têm grande importância econômica (Moreira et al., 1992) e ecológica. A família Fabaceae (Leguminosae) é o terceiro maior grupo do reino vegetal, sendo constituída em sua maioria por árvores tropicais (Sprent, 2001). As duas espécies de leguminosas arbóreas investigadas neste trabalho estáo presentes na regiáo Norte do Brasil, são elas: Hymenaea courbaril L. var. stillbocarpa (Hayne) Lee et Lang. e Enterolobium contortisiliquum (Vell.) Morong. Hymenaea courbaril L. var. stilbocarpa (Hayne) Lee et Lang. é classificada como espécie clímax, semidecídua, pouco exigente quanto à fertilidade do solo (Kageyama et al., 1990). A espécie possue uma polpa farinácea (Almeida et al., 1990), muito procurada por várias espécies da fauna, que dispersam suas sementes, por isso é muito indicada nos plantios em áreas degradadas destinadas à recomposiçấo da vegetaçấo arbórea. A altura é de $15-20 \mathrm{~m}$, as folhas são compostas de dois folíolos brilhantes, o fruto é um legume indeiscente, marrom, com 2-4 sementes (Lorenzi, 1992) e as flores estáo dispostas em panículas terminais contendo 4 sépalas verdecreme e 5 pétalas brancas a creme-alaranjada. Enterolobium contortisiliquum (Vell.) Morong. é uma espécie decídua, ótima para reflorestamento em plantios mistos de áreas degradadas, de preservaçáo permanente, principalmente por seu rápido crescimento inicial. Possui a altura de 20-35 metros, tronco cilíndrico, as folhas são compostas e bipinadas (Lorenzi, 1992), com 3 a 7 pares de pequenos folíolos oblongos, as inflorescências são tipo capítulo, globosas, com cerca de 10 a 20 flores brancas e os frutos são vagens, recurvadas e semilenhosas, surgem verdes e se tornam pretos.

O objetivo do presente trabalho foi avaliar os efeitos do nível de sombreamento no crescimento e o acúmulo de pigmentos fotossintéticos nas espécies $H$. courbaril $\mathrm{L}$. var. stilbocarpa (Hayne) Lee et Lang. e E. contortisiliquum (Vell.) Morong.

\section{MATERIAL E MÉTODOS}

O experimento foi conduzido no período de Maio a Setembro de 2006, no Centro Universitário Luterano de JiParaná (CEULJI/ULBRA), situado no município de Ji-Paraná, localizado na regiáo central do estado de Rondônia, à uma latitude sul de 10²'53" e longitude oeste de 61030'45", com altitude média de $159 \mathrm{~m}$. Segundo a classificação de Köppen, o clima da regiáo é caracterizado como CWa (tropical-quente e úmido). A temperatura média anual oscila em torno de $25^{\circ} \mathrm{C}$, e a precipitação pluviométrica anual de $2.250 \mathrm{~mm}$, com umidade relativa do ar média de $85 \%$.

As sementes de $H$. courbaril e E. contortisiliquum foram adquiridas da PREMIUM SEEDS, Florianópolis - SC. Estas sementes foram escarificadas com ácido sulfúrico concentrado por 1 hora, após este período, foram lavadas com água destilada em abundância. Em seguida, as sementes foram colocadas para germinar em caixas plásticas, contendo 2 folhas de papel de filtro no fundo, embebidas com água destilada. As caixas com as sementes foram mantidas em câmaras de germinaçáo à temperatura de $25^{\circ} \mathrm{C}$, sob fotoperíodo de 12 horas. Para manter a homogeneidade, após a germinaçáo, as plântulas de tamanho semelhante foram selecionadas e transferidas para vasos plásticos, com capacidade para 5,0 L, contendo substrato comercial Plantmax ${ }^{\oplus}$, composto a base de casca de pinus, com as seguintes características: $\mathrm{pH}=5,5-6,0$; relação $\mathrm{C} / \mathrm{N}=22 / 1$ e densidade $\left(\mathrm{kg} \cdot \mathrm{L}^{-1}\right)=0,47$.

Os tratamentos foram em número de quatro, representados pelos seguintes níveis de sombreamento: $0 \%$ (controle); 30 
$\% ; 50 \%$ e $80 \%$. O sombreamento foi determinado com tela plástica preta conhecida como sombrite. Nos tratamentos em que foram aplicados os sombreamentos, as plantas foram dispostas sob uma armação de madeira revestida de sombrite na parte superior e nas laterais. Cada armação foi dimensionada em 1,5 x 1,5 m na base e 1,4 m de altura. Para garantir que o sombreamento fosse determinado somente pelo sombrite as armaçôes foram colocadas em uma área aberta.

Após as mudas atingirem uma idade de quatro meses foram realizadas as seguintes análises: número de folhas, as folhas foram destacadas na inserção do pecíolo com o caule e posteriormente contadas; altura da planta, obtida por meio da medida do comprimento do caule, utilizou-se uma trena e mediu-se o comprimento do caule desde o colo até o seu ápice; comprimento do sistema radicular, a raiz de cada planta foi lavada e posteriormente o comprimento foi obtido tomando-se a medida desde o ápice da raiz até a base da planta; massa seca, as folhas, os caules e as raízes foram separados, colocados em sacos de papel e secados em estufa a $\pm 70{ }^{\circ} \mathrm{C}$, durante 48 horas, após este período, foi mensurada a massa seca; extração e dosagem de pigmentos fotossintéticos, a determinação de pigmentos foi segundo Hiscox \& Israelstam (1979), utilizando 0,1 g de massa fresca (MF) de folhas verde-maduras de cada espécie. $\mathrm{O}$ material vegetal foi imerso em $5 \mathrm{~mL}$ de dimetil-sulfóxido (DMSO), em tubos escuros e vedados. Os tubos foram deixados em bancada até extração total dos pigmentos. Após 36 horas, foram determinadas as absorbâncias. A concentração de pigmentos foi calculada de acordo com a equação de Arnon (1949) e Lichtenthaler (1987), conforme abaixo:

$$
\begin{aligned}
& \text { Clor. } a=\left(12,7 \cdot \mathrm{A}_{663}-2,69 \cdot \mathrm{A}_{645} / 1000 \mathrm{MS}\right) . \mathrm{V} \\
& \text { Clor. } b=\left(22,9 \cdot \mathrm{A}_{645}-4,68 \cdot \mathrm{A}_{663} / 1000 \mathrm{MS}\right) . \mathrm{V} \\
& \text { Clor. Total }=\left(20,2 \cdot \mathrm{A}_{645}-8,02 \cdot \mathrm{A}_{663} / 1000 \mathrm{MS}\right) . \mathrm{V} \\
& \text { Carotenóides }=\left(1000 \cdot \mathrm{A}_{470}\right)-(1,82 \cdot \text { Clor } a)-(85,02 . \text { Clor }
\end{aligned}
$$
b)/(198).V

Onde: $\mathrm{A}_{470}=$ absorbância a $470 \mathrm{~nm} ; \mathrm{A}_{663}=$ absorbância a $663 \mathrm{~nm} ; \mathrm{A}_{645}=$ absorbância a $645 \mathrm{~nm} ; \mathrm{V}=$ volume da amostra $(\mathrm{mL}) ; \mathrm{MS}=$ massa seca da amostra $(\mathrm{g})$

Os teores de clorofila e carotenóides foram expressos em mg. $\mathrm{g}^{-1}$ MS. Para a obtenção da MS, utilizado nesse calculo, foi pesado $0,1 \mathrm{~g}$ de MF das mesmas folhas utilizadas para a extraçáo de pigmentos, após esse material foi colocados em saquinhos de papel e secados em estufa a $\pm 70{ }^{\circ} \mathrm{C}$, durante 48 horas e depois novamente pesados.

Cada tratamento foi constituído de três repetiçóes de cada espécie estudada, sendo que cada repetição foi representada por uma muda. Dentro de cada tratamento, as repetiçóes foram dispostas em delineamento experimental inteiramente casualisado. Os dados coletados foram submetidos a análise de variância simples e nos casos significativos foi aplicado o teste de médias de Duncan ao nível de 5\% de probabilidade.

\section{RESULTADOS E DISCUSSÃO}

As plantas de $H$. courbarile E. contortisiliquum expostas ao tratamento com sol pleno, apresentaram um número de folhas inferior aos dos tratamentos 30, 50 e $80 \%$ de sombreamento (Tabelas 1 e 2). Porém, nas plantas de $H$. courbaril não houve diferenças entre 30 e $50 \%$ e entre 50 e $80 \%$. Enterolobium contortisiliquum não apresentou diferenciação entre 30, 50 e $80 \%$. Carvalho et al. (2006) verificaram em plantas de licuri (Syagrus coronata (Mart.) Becc.), que o tratamento a sol pleno também promoveu menor número de folhas em relação aos outros tratamentos com sombra. Entretanto, Aguiar et al. (2005) estudando esta variável em mudas de pau-brasil (Caesalpinia echinata Lam.), em função dos níveis sombreamento (pleno sol, 20, 40, 60 e 80\%) aos 12,18 e 24 meses de idade verificaram que essa variável não apresentou diferenças significativas entre os tratamentos e os meses de avaliação. Campos \& Uchida (2002) verificaram que não houve diferenciação entre os sombreamentos em relação ao número de folhas em plantas de $H$. courbaril. As folhas são o principal órgão fotossintético (Taiz \& Zeiger, 2002). Dessa forma, para aumentar a absorção de luz e maximizar o ganho total de carbono, as folhas sofrem alteraçóes morfológicas e fisiológicas (Osunkoya et al., 1994). Como por exemplo, a área foliar (folhas mais finas e maiores), a alocação de biomassa nas folhas (Poorter, 1999) e a quantidade das folhas, que tendem a aumentar com o acréscimo do nível do sombreamento.

A maior média para a altura da planta de $H$. courbaril foi obtida com o nível de sombreamento de $50 \%$ e em E. contortisiliquum com $30 \%$. O tratamento ao sol pleno promoveu as menores médias dessa variável nas duas plantas (Tabelas 1 e 2). Em plantas de canela-batalha (Cryptocarya aschersoniana Mez.) o maior crescimento em altura foi obtido no tratamento de $50 \%$ de sombreamento (Almeida et al., 2004). Mazzei et al. (1999), Paez et al. (2000) e Chaves e Paiva (2004) também verificaram que o sombreamento promoveu maior altura das plantas. Um importante mecanismo de adaptação das espécies é a capacidade de crescer rapidamente quando sombreada o que constitui uma valiosa estratégia para escapar às condiçóes de baixa intensidade luminosa (Moraes Neto et al., 2000). Contudo, alguns autores inferiram que o fator luz e sombra não influenciam a determinação da altura das plantas (Souza-Silva et al., 1999).

Em relação ao comprimento do sistema radicular nas plantas de $H$. courbaril e $E$. contortisiliquum, houve um aumento progressivo com o acréscimo do nível de sombreamento, porém não houve diferenças entre 0 e $30 \%$, 30 e $50 \%$ e 50 e $80 \%$ na primeira espécie (Tabela 1) e na segunda não houve diferenciação entre 50\% e 80\% (Tabela 2). 
Em plantas de caroba (Jacarandá copaia (Aubl.) D. Don.), o comprimento do sistema radicular não foi afetado pelos níveis de sombreamento (Campos \& Uchida, 2002).

Tabela 1 - Número de folhas, altura da planta, comprimento do sistema radicular e massa seca total em plantas de Hymenaea courbaril, com quatro meses de idade, submetidas a diferentes níveis de sombreamento.

\begin{tabular}{|c|c|c|c|c|}
\hline \multicolumn{5}{|c|}{ Hymenaea courbaril } \\
\hline \multirow[t]{2}{*}{ Sombreamentos } & \multirow{2}{*}{$\begin{array}{l}\text { № de } \\
\text { Folhas }\end{array}$} & $\begin{array}{c}\text { Altura da } \\
\text { planta }\end{array}$ & $\begin{array}{c}\text { Sistema } \\
\text { Radicular }\end{array}$ & $\begin{array}{c}\text { Massa Seca } \\
\text { Total }\end{array}$ \\
\hline & & \multicolumn{2}{|c|}{ (cm) } & (g) \\
\hline $0 \%$ & $7,00 \mathrm{c}$ & $41,67 \mathrm{c}$ & $43,17 \mathrm{c}$ & $2,60 \mathrm{c}$ \\
\hline $30 \%$ & $8,33 \mathrm{~b}$ & $45,90 \mathrm{~b}$ & $47,30 \mathrm{bc}$ & $4,10 \mathrm{~b}$ \\
\hline $50 \%$ & $9,33 a b$ & $54,20 \mathrm{a}$ & $51,07 a b$ & $4,03 \mathrm{~b}$ \\
\hline $80 \%$ & $10,00 \mathrm{a}$ & $46,73 \mathrm{~b}$ & $54,20 \mathrm{a}$ & $5,17 \mathrm{a}$ \\
\hline C.V. (\%) & 7,4 & 3,9 & 4,8 & 9,2 \\
\hline
\end{tabular}

Cada valor é a média de três replicações. Médias seguidas por letras distintas, na mesma coluna, diferem entre si, ao nível de $5 \%$ de probabilidade pelo teste de Duncan.

Tabela 2 - Número de folhas, altura da planta, comprimento do sistema radicular e massa seca total em plantas de Enterolobium contortisiliquum, com quatro meses de idade, submetidas a diferentes níveis de sombreamento.

\begin{tabular}{lcccc}
\hline \multicolumn{5}{c}{ Enterolobium contortisiliquum } \\
\hline \multirow{2}{*}{ Sombreamento } & $\begin{array}{c}\text { № de } \\
\text { Folhas }\end{array}$ & $\begin{array}{c}\text { Altura da } \\
\text { planta }\end{array}$ & $\begin{array}{c}\text { Sistema } \\
\text { Radicular }\end{array}$ & $\begin{array}{c}\text { Massa Seca } \\
\text { Total }\end{array}$ \\
\cline { 3 - 5 } & \multicolumn{3}{c}{$(\mathrm{cm})$} & $(\mathrm{g})$ \\
\hline $0 \%$ & $12,33 \mathrm{~b}$ & $87,67 \mathrm{~d}$ & $32,33 \mathrm{c}$ & $34,60 \mathrm{c}$ \\
$30 \%$ & $14,67 \mathrm{a}$ & $105,00 \mathrm{a}$ & $41,33 \mathrm{~b}$ & $37,33 \mathrm{~b}$ \\
$50 \%$ & $15,67 \mathrm{a}$ & $93,03 \mathrm{c}$ & $56,33 \mathrm{a}$ & $39,73 \mathrm{a}$ \\
$80 \%$ & $16,00 \mathrm{a}$ & $99,07 \mathrm{~b}$ & $57,80 \mathrm{a}$ & $40,47 \mathrm{a}$ \\
C.V. $(\%)$ & 7,6 & 2,3 & 7,9 & 3,3 \\
\hline
\end{tabular}

Cada valor é a média de três replicações. Médias seguidas por letras distintas, na mesma coluna, diferem entre si, ao nível de $5 \%$ de probabilidade pelo teste de Duncan.

O valor de massa seca total nas duas espécies estudadas submetidas a $80 \%$ foi superior a todos os outros, entretanto em E. contortisiliquum não houve diferença significativa entre $50 \%$ e $80 \%$ (Tabelas 1 e 2). Alguns autores verificaram também decréscimo na produção massa seca total em mudas cultivadas a pleno sol (Nakazono et al., 2001; Carvalho et al., 2006). A exposição prolongada a altas irradiâncias pode ser prejudicial às plântulas, por absorverem mais fótons de luz do que podem utilizar, podendo ter como conseqüência a fotoinibição ou, mesmo a morte da planta (Kitao et al., 2000).

As figuras 1 e 2 representam os resultados relacionados à razão clorofila $a / b$, clorofila total e carotenóides. Nas duas espécies estudadas a razão clorofila $a / b$ diminui com acréscimo do nível de sombreamento, porém em alguns tratamentos não houve diferenças significativas. Resultado semelhante foi verificado por Lima Júnior et al. (2005). Em geral, a proporçâo entre clorofila $a$ e $b$ decresce com o aumento do sombreamento (Kozlowski et al., 1991), devido a maior concentração de clorofila $b$. Essa concentração se deve a degradação mais lenta da clorofila $b$ em relação à clorofila $a$ (Engel e Poggiani, 1991) e a maior proporção do fotossistema II que é mais rico em clorofila $b$ (Nakazono et al., 2001). Dessa forma, a capacidade das plantas em maximizar a captura por luz em ambientes sombreados está principalmente relacionada com a relaçáo clorofila a/b (Engel \& Poggiani, 1991). Kappel \& Flore (1983), Castro et al. (1996) e Lee et al. (2000) verificaram resultados contrários, os maiores valores da relação clorofila $a / b$ ocorreram em condiçóes sombreadas.

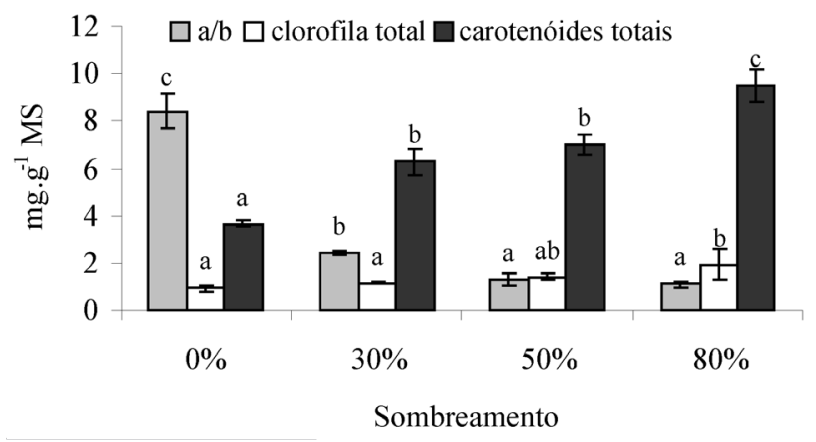

Figura 1 - Razão clorofila a/b, clorofila total e carotenóides em plantas de Hymenaea courbaril, com quatro meses de idade, submetidas a diferentes níveis de sombreamento; $0 \%$ (sol pleno), 30\%, 50\% e 80\%. Cada coluna é média de três replicações e as barras indicam o desvio padrão da média. Médias seguidas por letras distintas diferem entre si, ao nível de $5 \%$ de probabilidade pelo teste de Duncan. C.V. $=12,3 \%$ razão clorofila $a / b-23,6 \%$ clorofila total - 7,5\% carotenóides.

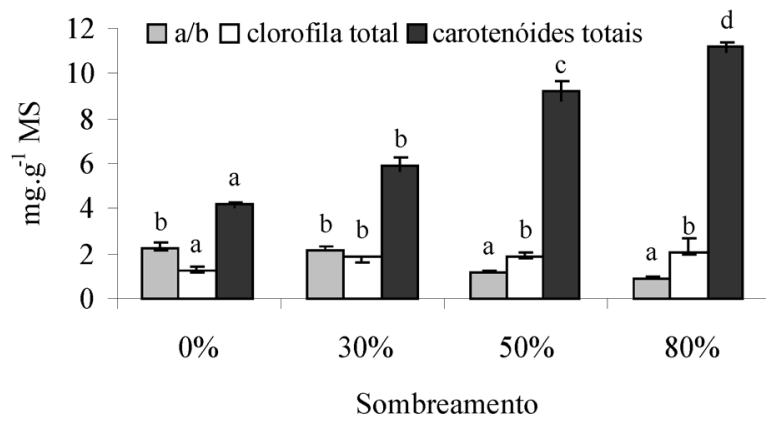

Figura 2 - Razão clorofila a/b, clorofila total e carotenóides em plantas de Enterolobium contortisiliquum, com quatro meses de idade, submetidas a diferentes níveis de sombreamento; $0 \%$ (sol pleno), 30\%, 50\% e 80\%. Cada coluna é média de três replicações e as barras indicam o desvio padrão da média. Médias seguidas por letras distintas diferem entre si, ao nível de $5 \%$ de probabilidade pelo teste de Duncan. C.V. $=10,2 \%$ razão clorofila a/b $-8,3 \%$ clorofila total - 3,9\% carotenóides.

A concentração de clorofila total aumentou com acréscimo do nível de sombreamento, nas duas espécies estudadas (Figuras 1 e 2). Entretanto, entre os tratamentos $0 \%, 30 \%$ e $50 \%$ e entre $50 \%$ e $80 \%$ as médias para os valores de clorofila total em plantas de $H$. courbaril não diferiram entre si. Em $E$. contortisiliquum, os tratamentos 30\%, 50\% e 80\% também não apresentaram diferenciação. Os resultados são semelhantes aos citados na literatura (Ellsworth \& Reich, 1992; Mendes et al., 2001; Alvarenga et al., 2003; Kitajima \& Hogan, 2003; Lima Júnior et al., 2005). Em condiçôes adequadas 
de intensidade luminosa as moléculas de clorofilas estão constantemente sendo degradadas e sintetizadas, na mesma proporção. Sob radiaçôes intensas, o processo degradativo ocorre de forma pronunciada, portanto folhas de sombra possuem maiores concentraçóes de clorofila total (Kramer \& Kozlowski, 1979). O maior acúmulo de clorofila nos níveis de maior sombreamento pode ser devido à compensação da espécie a menor quantidade de radiação disponível.

Os maiores valores para carotenóides foram adquiridos quando as plantas de $H$. courbaril e $E$. contortisiliquum foram cultivadas a $80 \%$ de sombreamento, diferindo entre todos os outros tratamentos (Figuras 1 e 2). Geralmente, os carotenóides tendem a aumentar com a redução da intensidade luminosa (Ferraz \& Silva, 2001). Estes pigmentos durante a fotossíntese podem desempenhar duas funções distintas: absorção de luz nos complexos de captação de luz atuando como pigmentos acessórios e atuando como fotoprotetores do aparato fotoquímico (Kerbauy, 2004), prevendo danos fotooxidativos às moléculas de clorofila (Raven, et al., 2001). Provavelmente, nas espécies estudadas, a primeira função foi a mais exigida em ambientes sombreados e a segunda quando as plantas foram expostas à alta irradiância.

\section{CONCLUSÃO}

O cultivo sob sol pleno afetou negativamente o crescimento das plantas de $H$. courbaril e E. contortisiliquum.

O sombreamento em $H$. courbaril e $E$. contortisiliquum favorece para formação de mudas mais vigorosas

O acréscimo do nível do sombreamento provocou uma menor relaçấo clorofila $a / b$ e aumento nas concentraçóes de clorofila total e carotenóides totais.

\section{AGRADECIMENTOS}

Ao Centro Universitário Luterano de Ji-Paranál Universidade Luterana do Brasil (CEULJI/ULBRA), Rondônia, principalmente pelo apoio financeiro para desenvolvimento do trabalho.

\section{BIBLIOGRAFIA CITADA}

Aguiar, F.F.A.; Kanashiro, S.; Tavares, A.R.; Pinto, M.M.; Stancato, G.C.; Aguiar, J.; Nascimento, T.D.R. 2005. Germinaçáo de sementes e formaçấo de mudas de Caesalpinia echinata Lam. (pau-brasil): efeito de sombreamento. Revista Árvore, 29: 871-875.

Almeida, L.P.; Alvarenga, A.A.; Castro, E.M.; Zanela, S.M.; Vieira, C.V. 2004. Crescimento inicial de plantas de Cryptocaria aschersoniana Mez. submetidas a níveis de radiação solar. Ciência Rural, 34: 83-88.

Almeida, L.S.; Maia, N.; Ortega, A.R.; Ângelo, A.C. 2005. Crescimento de mudas de Jacaranda puberula cham. em viveiro submetidas a diferentes níveis de luminosidade. Ciência Florestal, 15: 323-329.

Almeida, S.P.; Silva, J.A.; Ribeiro, J. 1990. Aproveitamento alimentar de espécies nativas do cerrado: araticum, barú, cagaita e jatobá. 2 ed. Embrapa-CPAC, Planaltina, 83pp. (Documentos 26).

Alvarenga, A.A.; Castro, E.M.; Lima Júnior, É.C.; Magalhães, M.M. 2003. Effects of different light levels on the initial growth and photosynthesis of Croton urucurana Baill. In southeaster Brazil. Revista Árvore, 27: 53-57.

Arnon, D.J. 1949. Copper enzymes in isolated chloroplast polyphenoloxidases in Beta vulgaris. Plant Physiology, 24: $1-15$.

Campos, M.A.A.; Uchida, T. 2002. Influência do sombreamento no crescimento de mudas de três espécies amazônica. Pesquisa Agropecuária Brasileira, 37: 281-288.

Carvalho, N.O.S.; Pelacani, C.R.; Rodrigues, M.O.S.; Crepaldi, I.C. 2006. Crescimento inicial de plantas de licuri (Syagrus coronata (Mart.) Becc.) em diferentes níveis de luminosidade. Revista Árvore, 30: 351-357.

Castro, E.M.; Alvarenga, A.A.; Gomide, M.B. 1996. Crescimento e distribuição de matéria seca de mudas de calabura (Muntingia calabura L.) submetidas a três diferentes níveis de irradiância. Ciência e Agrotecnologia, 20: 357-365.

Chaves, A.S.; Paiva, H.N. 2004. Influência de diferentes períodos de sombreamento sobre a qualidade de mudas de fedegoso (Senna macranthera (Collad). Irwin et Barn.). Scientia Forestalis, 65: 22-29.

Ellsworth, D.S.; Reich, P.B. 1992. Leaf mass per area, nitrogen content and photosynthetic carbon gain in Acer saccharum seed- lings in contrasting forest light environments. Functional Ecology, 6: 423-435.

Engel, V.L. 1989. Influência do sombreamento sobre o crescimento de mudas de essências nativas, concentração de clorofila nas folhas e aspectos de anatomia. Dissertação de Mestrado, Escola Superior de Agricultura "Luiz de Queiroz", Piracicaba, São Paulo. 202pp.

Engel, V.L.; Poggiani, F. 1991. Estudo da concentração de clorofila nas folhas e seu espectro de absorção de luz em função do sombreamento em mudas de quatro espécies florestais nativas. Revista Brasileira de Fisiologia Vegetal, 3: 39-45.

Ferraz, K.K.F.; Silva, D.M. 2001. Avaliação ecofisiológica do crescimento inicial de espécies florestais usadas na recuperação de áreas degradadas - II. Calliandracalothyrsus Meisn. p. 6-087. In: VIII Congresso Brasileiro de Fisiologia Vegetal, Anais... Ilhéus: SBFV, CD-ROM.

Hiscox, J.D.; Israelstam, G.F. 1979. A method for the extraction of chlorophyll from leaf tissue without maceration. Canadian Journal of Botany, 57: 1332-1334.

Kageyama, P.Y.; Biella, L.C.; Palermo Jr., A. 1990. Plantaçóes mistas com espécies nativas com fins de proteção a reservatórios. p. 109-113. In: Congresso Florestal Brasileiro, 6, Anais. Campos do Jordão: SBS/SBEF.

Kappel, F.; Flore, J.A. 1983. Effect of shade on photosynthesis, specific leaf weight chlorophyll content of leaves and morphology 
of young peach trees. Journal of the American Society of Horticultural Science, 108: 541-544.

Kerbauy, G.B. 2004. Fisiologia Vegetal. Guanabara Koogan, Rio de Janeiro, RJ, Brasil. 452pp.

Kitajima, K.; Hogan, K.P. 2003. Increases of chlorophyll $a / b$ ratios during acclimation of tropical woody seedlings to nitrogen limitation and high light. Plant Cell and Environmental, 26: 857-865.

Kitao, M.; Lei, T.T.; Koike, T.; Tobita, H.; Maruyama,Y. 2000. Susceptibility to photoinhibition of three deciduous broadleaf tree species with different successional traits raised under various light regimes. Plant Cell and Environmental, 23: 81-89.

Kozlowski, T.; Kramer, P.J.; Pallardy, S.G. 1991. The physiological ecology of woody plants. Academic Press, London, 657pp.

Kramer, T.; Kozlowski, T. 1979. Physiology of woody plants. Academic, New York, USA, 811pp.

Lee, D.W.; Oberbauer, F.; Johnson, P.; Baskaran, K.; Mansor, M.; Mohamad, H.; Yap, S.K. 2000. Effects of irradiance and spectral quality on leaf structure and function in seedlings of two Southeast Asian Hopea (Dipterocarpaceae) species. Americam Journal of Botany, 87: 447-455.

Lichtenthaler, B.K. 1987. Chlorophylls and carotenoids: pigments of photosynthetic biomembranes. Methods in Enzimology, 148: 350-382.

Lima Júnior, É.C.; Alvarenga, A.A. de; Castro, E.M. de; Vieira, C.V.; Barbosa, J.P.R.A.D. 2006. Aspectos fisioanatômicos de plantas jovens de Cupania vernalis Camb. submetidas a diferentes níveis de sombreamento. Árvore, 30: 33-41.

Lima Júnior, É.C.; Alvarenga, A.A. de; Castro, E.M. de; Vieira, C.V; Oliveira, H.M. 2005. Trocas gasosas, características das folhas e crescimento de plantas jovens de Cupania vernalis Camb. submetidas a diferentes níveis de sombreamento. Ciência Rural, 35: 1092-1097.

Lima, A.L.S.; DaMatta, F.M.; Pinheiro, H.A.; Tótola, M.R.; Loureiro, M.E. 2002. Photochemical responses and oxidative stress in two clones of Coffea canephora under water deficit conditions. Environmental and Experimental Botany, 47: 239-247.

Lorenzi, H. 1992. Árvores brasileiras. Plantarum, Nova Odessa, SP, BR. 352pp.

Mazzei, L.J.; Sousa-Silva, J.C.; Felfili, J.M.; Rezende, A.V.; Franco, A.C. 1999. Crescimento de plântulas de Hymenaea courbarilvar. stilbocarpa (Hayne) Lee \& Lang em viveiro. Boletim do Herbário Ezechias Paulo Heringer, 4: 21-29.

Mendes, M.M.; Gazarini, L.C.; Rodrigues, M.L. 2001. Acclimation of Myrtus communis to contrasting Mediterranean light environments - effects on structure and chemical composition of foliage and plant water relations. Environmental and Experimental Botany, 45: 165-178.

Monteiro, P.P.M.; Ramos, F.A. 1997. Beneficiamento e quebra de dormência de sementes em cinco espécies florestais do cerrado. Revista Árvore, 21: 169-174.
Moraes Neto, S.P.; Gonçalves, J.L.M.; Takaki, M.; Cenci, S.; Gonçalves, J.C. 2000. Crescimento de mudas de algumas espécies arbóreas que ocorrem na Mata Atlântica, em função do nível de luminosidade. Revista Árvore, 24: 35-45.

Moreira, F.M.; Silva, M.F.; Faria, S.M. 1992. Occurrence of nodulation in legume species in the Amazon Region of Brazil. New Phytologist, 121: 563-570.

Nakazono, E.M.; Dacosta, M.; Futatsugi, K.; Paulilo, M.T.S. 2001. Early growth of Euterpe edulis Mart., in different light environments. Revista Brasileira de Botânica, 24: 173-179.

Osunkoya, O.O.; Ash, J.E.; Hopkins, M.S.; Graham, A.W. 1994. Influence of seed size and seedling ecological attributes on shade-tolerance in northern Queensland. Journal of Ecology, 82: 149-163.

Paez, A.; Gebre, G.M.; Çonçalves, M.E.; Tschaplinski, T.J. 2000. Growth, soluble carbohydrates, and aloin concentration of Aloe vera plants exposed to three irradiance levels. Environmental and Experimental Botany, 44: 133-139.

Poorter, L. 1999. Growth responses of 15 rain-forest tree species to a light gradient : the relative importance of morphological and physiological traits. Functional Ecology, 13: 396-410.

Raven, P.H.; Evert, R.F.; Eichhorn, S.E. 2001. Biologia Vegetal. Guanabara Koogan. Rio de Janeiro, RJ, BR. 906pp.

Scalon, S.P.Q.; Alvarenga, A.A. 1993. Efeito do sombreamento sobre a formação de mudas de pau-pereira (Platycyamus regnelli Benth.). Revista Árvore, 17: 265-270.

Scalon, S.P.Q.; Mussury, R.M.; Rigoni, M.R.; Scalon Filho, H. 2003. Crescimento inicial de mudas de Bombacopsis glabra (Pasq.) A. Robyns sob condição de sombreamento. Revista Árvore, 27: 753-758.

Sousa-Silva, J.C.; Salgado, M.A.S.; Felfili, J.M.; Rezende, A.V.; Franco, A.C. 1999. Desenvolvimento inicial de Cabralea canjerana Saldanha em diferentes condiçóes de luz. Boletim do Herbário Ezechias Paulo Heringer, 4: 80-89.

Sprent, J.I. 2001. Nodulation in legume. Royal Botanic Gardens Kew. Great Britain. 46pp.

Taiz, L.; Zeiger, E. 2002. Plant Physiology. Sinauer Associates, Sunderland, MA, USA. 690pp.

Zanella, F.; Soncela, R.; Lima, A.L.S. 2006. Crescimento e acúmulo de pigmentos fotossintéticos em mudas de maracujá-amarelo (Passiflora edulis Sims f. flavicarpa Deg.) formadas sob diferentes níveis de sombreamento. Ciência e Agrotecnologia, 30: 880884 .

Recebido em: 22/11/2007

Aceito em: 28/09/2009 